\section{Shear-wave elastography in breast ultrasonography: the state of the art}

\author{
Ji Hyun Youk, Hye Mi Gweon, Eun Ju Son \\ Department of Radiology, Gangnam Severance Hospital, Yonsei University College of \\ Medicine, Seoul, Korea
}

Shear-wave elastography (SWE) is a recently developed ultrasound technique that can visualize and measure tissue elasticity. In breast ultrasonography, SWE has been shown to be useful for differentiating benign breast lesions from malignant breast lesions, and it has been suggested that SWE enhances the diagnostic performance of ultrasonography, potentially improving the specificity of conventional ultrasonography using the Breast Imaging Reporting and Data System criteria. More recently, not only has SWE been proven useful for the diagnosis of breast cancer, but has also been shown to provide valuable information that can be used as a preoperative predictor of the prognosis or response to chemotherapy.

Keywords: Breast; Ultrasonography; Elasticity imaging techniques

\section{Introduction}

Elastography is an imaging modality based on tissue stiffness or hardness, which is analogous to clinical palpation with ultrasonography for a malignancy $[1,2]$. Unlike a physical examination, which allows only the subjective judgment of the stiffness of a lesion, elastography has the potential to quantify stiffness [2]. In breast ultrasonography, two elastographic techniques are popular and differ in the type of stress applied: strain and shear-wave elastography (SWE) [3]. Strain elastography produces an image based on the relative displacement of the tissue from an external (manual compression of the transducer) or patient source. It is difficult to measure the amount of the force or stress during compression, and the absolute elasticity cannot be calculated [2,3]. Meanwhile, SWE using the acoustic radiation force induced by the ultrasound push pulse generated by the transducer provides quantitative elasticity parameters, as well as displaying a visual color overlay of elastic information in real time $[2,3]$. In this article, the clinical applications and the current role of SWE in breast ultrasonography are reviewed.

\section{Image and Data Acquisition}

With shear waves that are induced by the acoustic radiation force and propagate transversely in the tissue, SWE can provide a semitransparent color-coded image displaying the shear wave velocity $(\mathrm{m} / \mathrm{sec})$ or elasticity $(\mathrm{kPa})$ for each pixel in real time, because the speed of the shear waves can be measured and is linked to the Young modulus ( $\mathrm{KPa}$ ) [3-6]. To obtain SWE images of breast lesions, the rectangular field-of-view box of the system is set to include the lesion itself as well as the

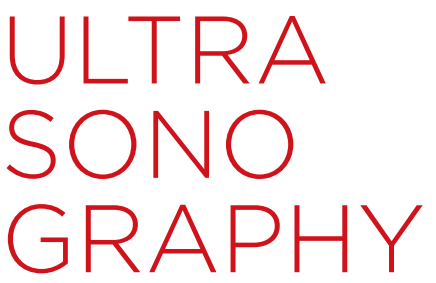

\section{REVIEW ARTICLE}

https://doi.org/10.14366/usg. 17024 pISSN: 2288-5919 - elSSN: 2288-5943 Ultrasonography 2017;36:300-309

Received: March 8, 2017

Revised: April 3, 2017

Accepted: April 5, 2017

Correspondence to: Ji Hyun Youk, MD, Department of Radiology, Gangnam Severance Hospital, Yonsei University College of Medicine, 211 Eonju-ro, Gangnam-gu, Seoul 06273, Korea

Tel. $+82-2-2019-3510$

Fax. $+82-2-3462-5472$

E-mail: jhyouk@yuhs.ac

This is an Open Access article distributed under the terms of the Creative Commons Attribution NonCommercial License (http://creativecommons.org/ licenses/by-nc/3.0/) which permits unrestricted noncommercial use, distribution, and reproduction in any medium, provided the original work is properly cited.

Copyright (C) 2017 Korean Society of Ultrasound in Medicine (KSUM)

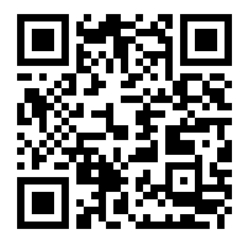

How to cite this article:

Youk JH, Gweon HM, Son EJ. Shear-wave elastography in breast ultrasonography: the state of the art. Ultrasonography. 2017 0ct;36(4):300-309. 
surrounding normal tissue; in this display, the tissue stiffness of each pixel in the image is shown as a semitransparent color map overlaid on the gray-scale image. The size of the rectangular region of interest (ROI) should be large enough to reveal any perilesional increased stiffness, because the maximum areas of stiffness in malignant lesions are almost always found in the area immediately adjacent to the lesions rather than in the lesion itself, and large enough to include normal fat tissue for the measurement of the lesion-to-fat ratio of elasticity (Fig. 1) $[7,8]$. In general, the range of the color scale within the ROI for breast lesions is from 0 (dark

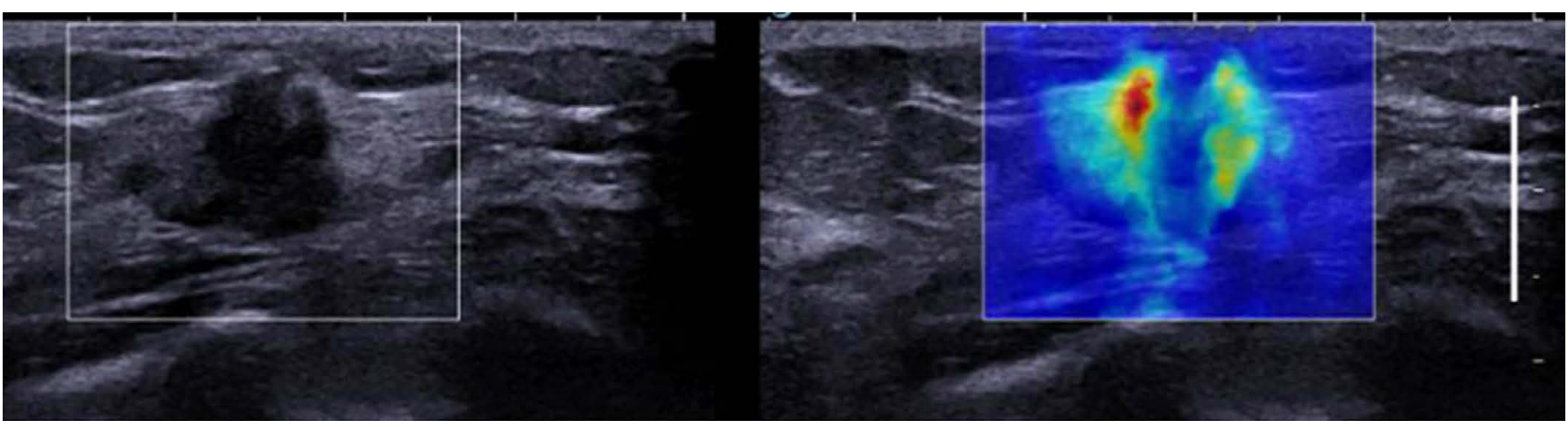

A

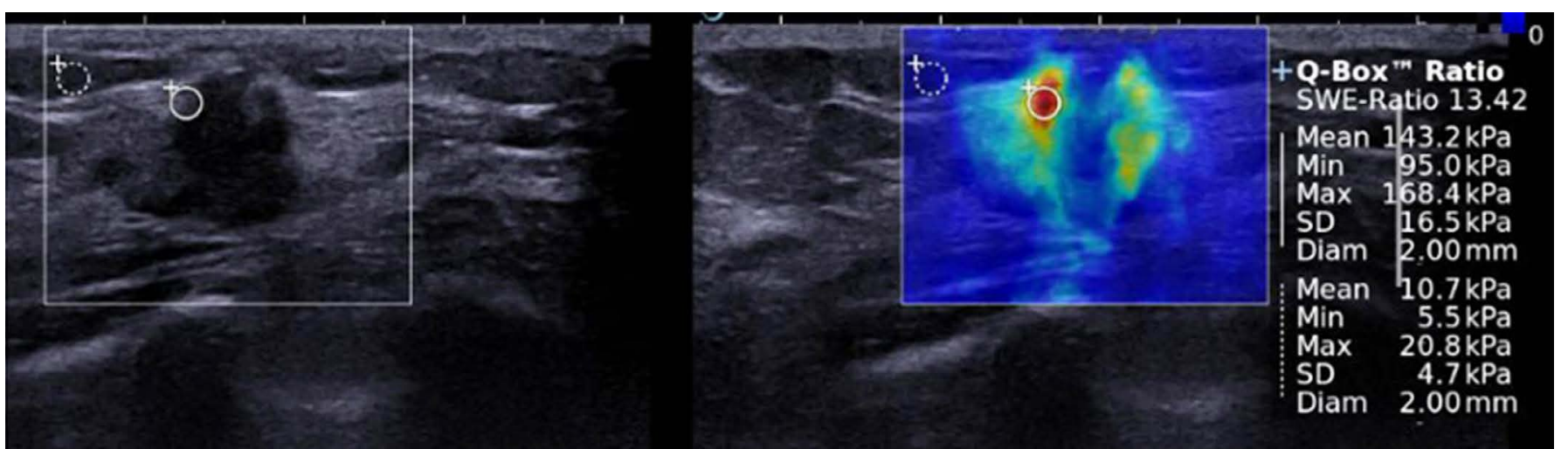

B

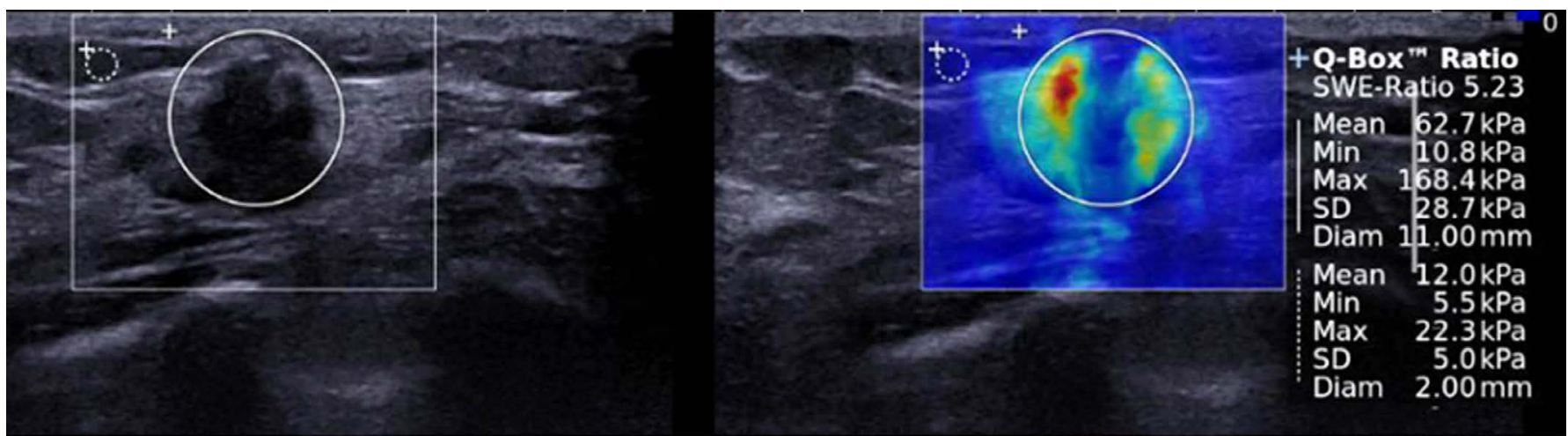

C

Fig. 1. A 38-year-old woman with a pathologically proven invasive ductal carcinoma.

A. Shear-wave elastography (right) and B-mode images (left) on split-screen mode show a 13-mm, irregular mass with red, heterogeneous elasticity. B. The mean, minimum, maximum, and standard deviation of elasticity values were measured in kPa by placing the region of interest (ROI) over the stiffest part of the lesion (circle). The elasticity ratio of the mass to the reference fat tissue was measured by placing a second ROI over the surrounding fat tissue (dotted circle). C. The ROI for measuring the elasticity value was placed to include the whole breast lesion and the stiffest part of the lesion. 
blue, indicating the lowest stiffness) to $180 \mathrm{kPa}$ (red, indicating the highest stiffness), but the color scale can be adjusted to enhance the contrast of elasticity on the color map without any change in the absolute elasticity values [7].

To obtain high-quality SWE images, obtaining a good gray-scale image is essential before switching to the SWE mode because elastography images are often generated based on raw data from gray-scale images [9]. Since vibration energy is directly emitted from the probe, it is important to keep the angle of the probe perpendicular to the skin and the probe lightly touching the skin without consciously applying any vibration or compression $[9,10]$. If excessive compression or movement of the probe is applied, artifactual stiffness other than the target lesion is displayed as yellow to red, generally radiating from the skin surface or chest wall; this could be misinterpreted as high elasticity, even in a soft lesion. Using generous amounts of contact jelly and having the patient hold her breath may be effective in some cases to reduce artifacts $[5,10]$. Since it usually takes a few to several seconds for the color map of SWE to stabilize, depending on the case and the operator's skill, the probe should be held still until the color display is completely stable before recording SWE images and measuring the elasticity of lesions in order to ensure that reliable results are obtained $[9,10]$.

To measure the elasticity quantitatively in SWE for breast lesions, the most common practice is to place a 2- to 3-mm circular ROI over the stiffest part of the lesion, including the immediately adjacent stiff tissue or halo (Fig. 1). The elasticity parameters, including the mean $\left(E_{\text {mean }}\right)$, maximum $\left(E_{\text {max }}\right)$, minimum $\left(E_{\text {min }}\right)$, and standard deviation $\left(E_{S D}\right)$ of elasticity, are calculated automatically from the elasticity value of each pixel included in the ROI and displayed on the monitor of the ultrasound device in $\mathrm{kPa}$ or $\mathrm{m} / \mathrm{sec}$ (Fig. 1). However, the size or shape of the ROI can be adjusted by the operator. In a previous study, the diagnostic performance of SWE, including its sensitivity, specificity, and accuracy, was influenced by the size of the ROI and varied across the elasticity parameters; therefore, the evaluation of all parameters with a 2-mm ROI was recommended [11]. In addition, a larger circular ROI encompassing the entire lesion as well as the stiffest part of the lesion can be used to quantify the elastic heterogeneity of a breast lesion by measuring $E_{S D}$ during SWE with good diagnostic performance (Fig. 1C) [12]. However, it is difficult to completely enclose irregular lesions with a circular ROI. To overcome this limitation, freehand ROI drawing techniques have been developed recently and are now commercially available (Fig. 2). The elasticity ratio $\left(E_{\text {ratio }}\right)$ of the breast lesion to the reference fat tissue can be measured by placing the first ROI over the stiffest part of the lesion, including the immediately adjacent stiff tissue or halo, and a second ROI in the fatty tissue of the breast (Fig. 1) [8]. Although the $\mathrm{ROI}$ for the reference fat can be set in various locations, since the diagnostic performance of $E_{\text {ratio }}$ was found not to be influenced by the measurement site of fat elasticity, images with a good quality should be obtained and the ROls for the lesion and the surrounding fat should be set in areas without artifacts to avoid false-positive or -negative results [8]. Regarding the image acquisition planes, two orthogonal SWE images are recommended rather than a single SWE image, because breast tumors with intratumoral heterogeneity can appear to have different elasticity according to the selected imaging plane, just as they can show different morphology in grayscale images [13]. It is recommended to select the higher elasticity score when two SWE images have a similar image quality but show a discordant finding, and to select the elasticity score of the SWE with the higher image quality when the image quality of the other SWE image is poor. To obtain much more elasticity information about a breast lesion in further planes, including the stiffest plane, 3-dimensional (3D) SWE can be used, which provides 3D volumetric color-coded elasticity maps of tissue stiffness in a single acquisition (Fig. 3) [14]. Unlike 2-dimensional SWE, in which the representative plane of the breast mass is chosen at the discretion of the operator

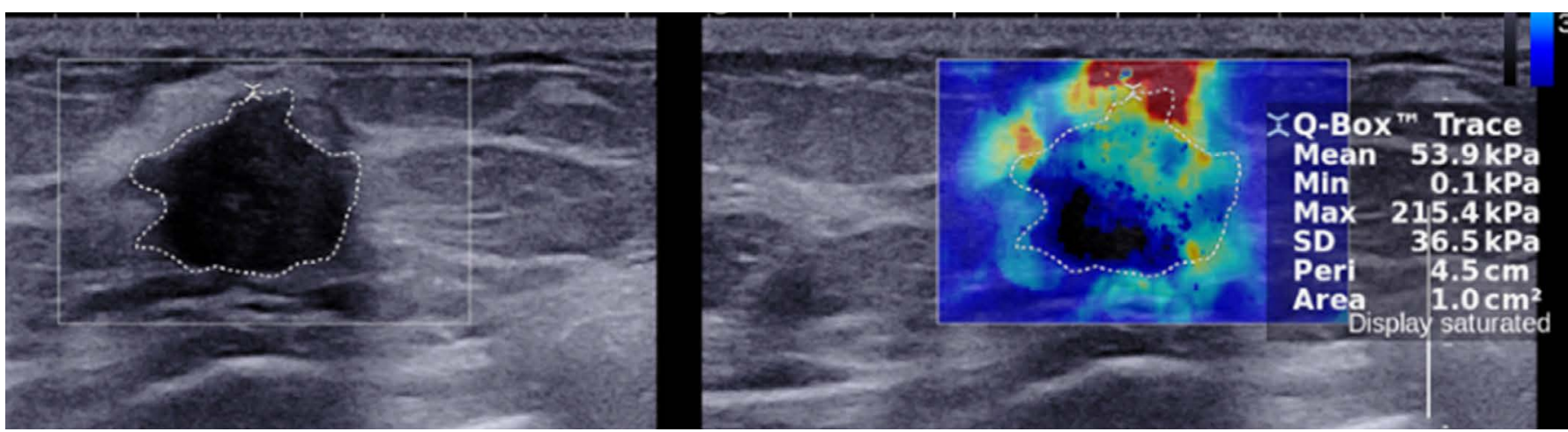

Fig. 2. A 42-year-old woman with a pathologically proven invasive ductal carcinoma. A freehand region of interest was drawn manually by tracing the border of the mass using shear-wave elastography to measure lesion elasticity. 
and the stiffest portion of the tumor may be missed, 3D SWE can show the stiffest portion of the mass more easily and accurately [15].

\section{Image and Data Interpretation}

\section{Quantitative Method}

The breast tissue elasticity measured by SWE varies depending on the inherent tissue characteristics of the breast structures. For example, $E_{\text {mean }}$ measured in vivo by SWE ranges from 5 to $10 \mathrm{kPa}$ in fatty tissue and from 30 to $50 \mathrm{kPa}$ in breast parenchyma [16]. Pathologic conditions change breast tissue elasticity; in general, benign lesions tend to be harder than normal breast tissue but softer than malignant lesions [4]. In clinical practice, $E_{\text {mean },} E_{\max }, E_{S D \prime}$ and $E_{\text {ratio }}$ are popular quantitative SWE parameters in the differential diagnosis of breast lesions visible on ultrasonography. However, no clear consensus exists regarding the best quantitative parameter or the most appropriate cutoff values. The ranges of cutoff values between benign and malignant breast lesions for each parameter with 2-mm ROls have been reported to be as follows: 33.3-80 $\mathrm{kPa}$ (median, $59.35 \mathrm{kPa}$ ) for $\mathrm{E}_{\text {meani }}$ 46.7-93.8 $\mathrm{kPa}$ (median, 79.25 $\mathrm{kPa}$ ) for $\mathrm{E}_{\max } ; 6.3-13.9 \mathrm{kPa}$ (median, $9.8 \mathrm{kPa}$ ) for $\mathrm{E}_{\mathrm{SD}} ;$ and 3.18$5.14 \mathrm{kPa}$ (median, $3.56 \mathrm{kPa}$ ) for $\mathrm{E}_{\text {ratio }}[3,7,8,12,14,15,17-27]$. In the literature, $E_{\text {mean }}$ appears to be widely used in the diagnosis of breast lesions. However, ROI size should be considered when interpreting the results of $E_{\text {mean }}$. Because $E_{\text {mean }}$ is the sum of all elasticity values of each pixel within the ROI divided by the number of pixels, its absolute value depends on the size of the ROl; that is, a higher $E_{\text {mean }}$ value for a smaller ROI is expected [28]. $E_{S D}$

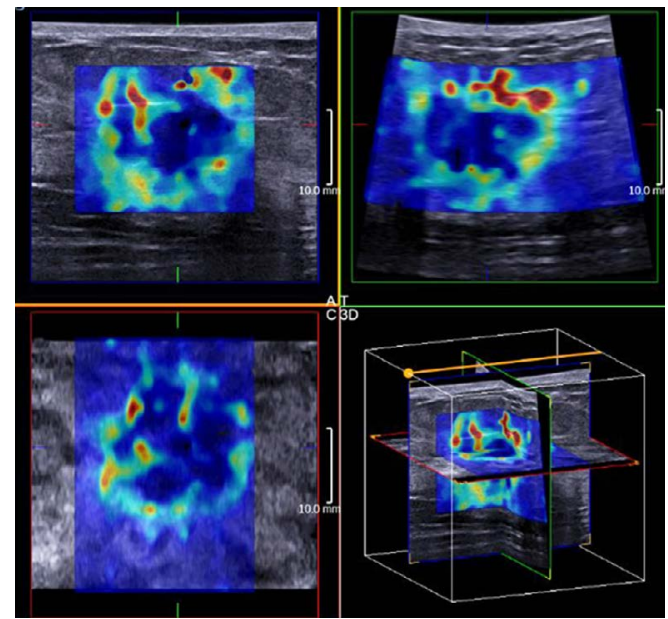

A

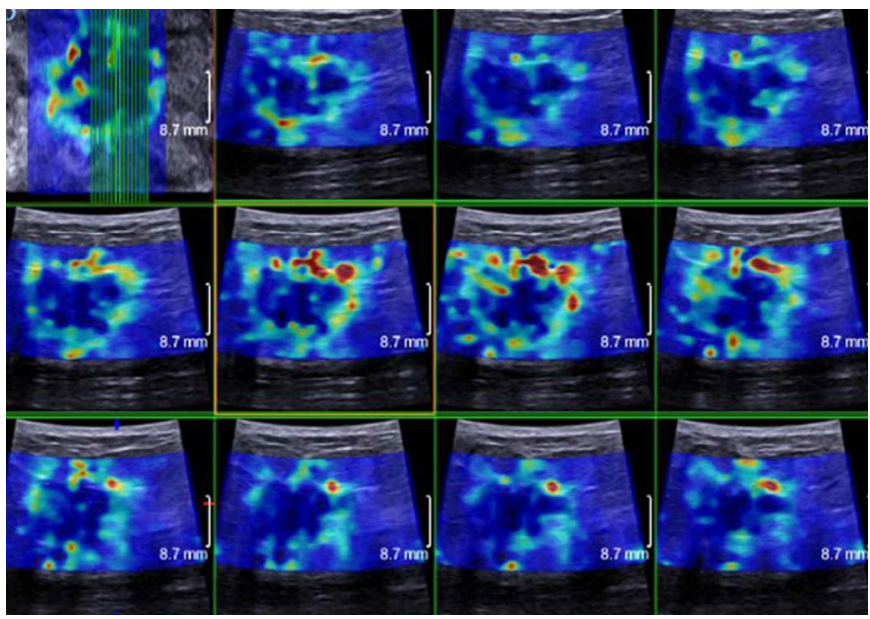

C

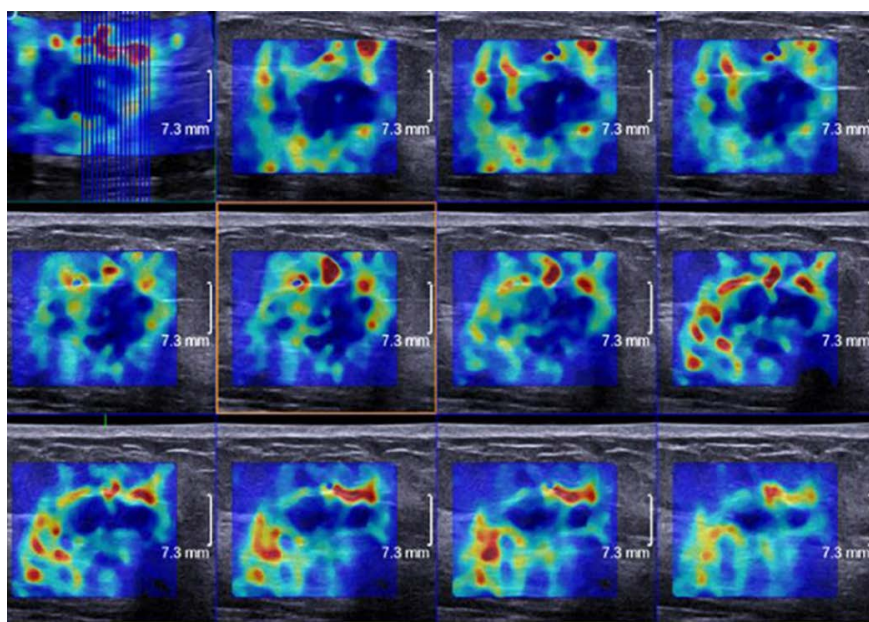

B

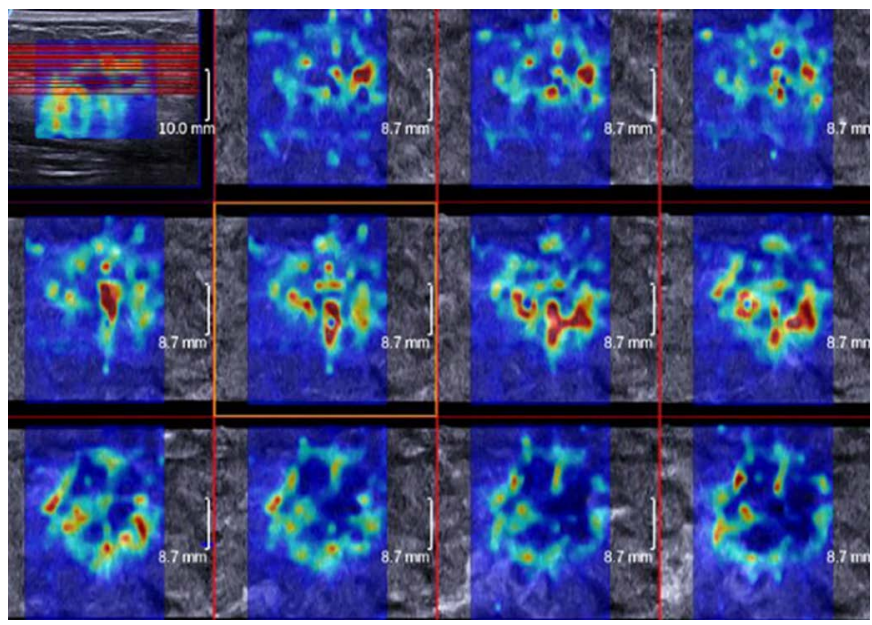

D

Fig. 3. A 58-year-old woman with a pathologically proven invasive ductal carcinoma.

Multiplanar (A) and multislice (B-D; B, axial; C, sagittal; and D, coronal) images in three-dimensional shear-wave elastography show red, heterogeneous elasticity of the mass. 
representing the average difference in elasticity value within the $R O I$ to $E_{\text {mean }}$ is also influenced by the ROI size [28]. As the size of the ROI changes, the sampling of the elasticity information becomes more variable, meaning that elastic heterogeneity will increase or decrease, particularly in a heterogeneous malignant lesion. For $E_{\max }$ however, the stiffest part of the mass is always included within the ROI, regardless of the size of the ROI, and its absolute value is independent of the ROI size. For $E_{\text {ratior }}$ the optimal measurement of reference fat elasticity is crucial, as fat elasticity is the denominator in calculating $E_{\text {ratior }}$ and even a small difference in fat elasticity can cause a large difference in $E_{\text {ratio }}$ [8]. In addition, SWE anisotropy-the difference in lesion elasticity measured in two orthogonal planescould be used in the diagnosis of breast lesions [28]. Malignant lesions are more anisotropic than benign lesions.

\section{Qualitative Method}

From a color-coded elasticity map displayed in real time on SWE, the elasticity of breast lesions can be qualitatively evaluated for their diagnosis. In general, color map features can be visually assessed on the spot before measuring elasticity quantitatively, making the qualitative method more instantaneous. The color displayed for each pixel represents the elasticity information of the corresponding tissue, and once the color map features of the lesion are screened, an ROI can be placed over the stiffest part of the lesion to measure the elasticity quantitatively. For the qualitative assessment of breast lesions on SWE, a 4-color pattern classification based on color stiffness and heterogeneity was proposed by Tozaki and Fukuma [29]: in pattern 1, no difference from the color around the lesion is observed at the margin of the lesion or in its interior (coded blue homogeneously); in pattern 2, a color that differs from the color around the lesion is observed at the margin or in the interior of the lesion, but it extends beyond the lesion and continues vertically in cords on the cutaneous side or the thoracic wall side (vertical stripe pattern artifacts); in pattern 3, a localized colored area is present at the margin of the lesion; and in pattern 4 , colored areas are present in the interior of the lesion heterogeneously (Fig. 4) $[29,30]$. Pattern 2 is a unique artifact frequently observed during SWE examinations, with reported ranges from $7 \%$ to $24 \%[24,29-31]$. Patterns 3 and 4 are characterized by peripheral increased stiffness (the "stiff rim sign") and heterogeneous color map features, suggestive of malignancy [7]. The stiff rim sign may be caused by (1) a desmoplastic reaction or the infiltration of cancer cells into the interstitial tissues or the intraductal component; or (2) internal low shear wave amplitude and/or noise as well as peripheral highspeed shear wave in the lesion caused by attenuation of the energy of the shear wave in the periphery of the lesion [7,32]. Elastic heterogeneity is regarded to represent histologic heterogeneity of malignant lesions that are in part more cellular due to lymphocytic infiltration and/or in part more necrotic [12]. Berg et al. [19] proposed qualitative $\mathrm{E}$ values, $\mathrm{E}_{\mathrm{col}}$ (a 6-point color score of maximum elasticity: red, orange, green, light blue, dark blue, or black), $E_{\text {homo }}$ (homogeneity of elasticity: very homogeneous, reasonably homogeneous, or heterogeneous), and $\mathrm{E}_{\text {sha }}$ (lesion shape: oval, round, or irregular).

In the fifth edition of the Breast Imaging Reporting and Data System (BI-RADS), descriptors for qualitative elasticity assessment were added: soft, intermediate, and hard. It is emphasized that a soft elastogram must not supersede morphologic analysis. Stiffness as a feature of malignant masses may be considered along with their much more important morphologic characteristics [33].

\section{Clinical Applications of SWE}

\section{Differentiation of Benign and Malignant Breast Lesions}

The diagnostic performance of SWE is good for differentiating between benign and malignant breast lesions. In literature, the median sensitivity, specificity, and area under receiver operating curve of each quantitative parameter have been reported as follows: $88.6 \%$ (range, $81.0 \%$ to $95.8 \%$ ), $89.9 \%$ (range, $68.2 \%$ to $93.8 \%$ ), and 0.932 (range, 0.788 to 0.974 ) for $\mathrm{E}_{\text {mean }} ; 90.3 \%$ (range, $60.9 \%$ to $97.0 \%$ ), $81.8 \%$ (range, $77 \%$ to $100 \%$ ), and 0.931 (range, 0.741 to 0.961 ) for $E_{\text {max }} ; 89.2 \%$ (range, $83.1 \%$ to $91.1 \%$ ), $91.1 \%$ (range, $67.9 \%$ to $93.0 \%$ ), and 0.899 (range, 0.761 to 0.964 ) for $E_{\text {sDi }}$ and $88.0 \%$ (range, $71.4 \%$ to $96.7 \%$ ), $93.7 \%$ (range, $90.6 \%$ to $100 \%$ ), and 0.952 (range, 0.917 to 0.987 ) for $E_{\text {ratior }}$ respectively $[3,6,7,12-$ $15,17,21-26,32,34-39]$. The best-performing SWE parameter in diagnosing breast lesions has been reported to be $E_{\max }$ or $E_{\text {ratio }}$ $[15,19,25,26,38,40]$.

The combination of SWE with conventional B-mode ultrasound increases the diagnostic performance for breast lesions, compared with conventional B-mode ultrasound alone $[3,4,7,18,19,25,26,34]$. In a meta-analysis, the sensitivity, specificity, and the area under receiver operating curve were reported as follows: $97.1 \%$ (95\% confidence interval [Cl], $94.1 \%$ to $98.6 \%), 80.1 \%(95 \% \mathrm{Cl}, 73.3 \%$ to $85.6 \%)$, and $0.96(95 \% \mathrm{Cl}, 0.94$ to 0.97$)$ for both techniques in combination; and $94.9 \%(95 \% \mathrm{Cl}, 88.1 \%$ to $97.9 \%)$ and $55.2 \%$ (95\% Cl, $26.4 \%$ to $80.9 \%$ ), and $0.93(95 \% \mathrm{Cl}, 0.90$ to 0.95$)$ for conventional B-mode ultrasound alone, respectively [41]. The use of SWE as an adjunct to conventional B-mode ultrasound can increase diagnostic confidence and improve patient management. More specifically, SWE features can help reclassify BI-RADS category 3 or 4 a lesions by morphologic criteria on conventional B-mode ultrasound. In the BE1 multinational prospective study, the use of SWE features to downgrade BI-RADS category 4a lesions to follow- 


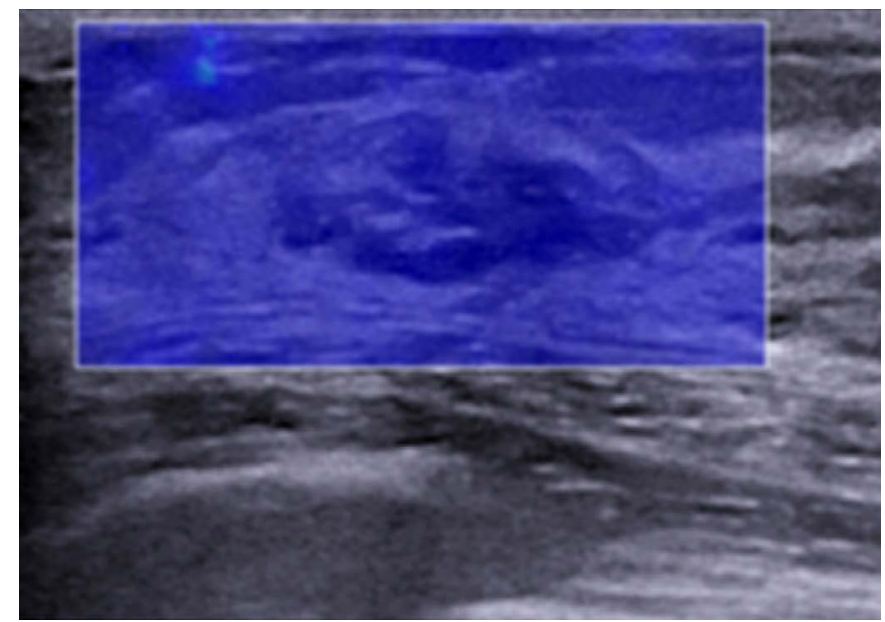

A

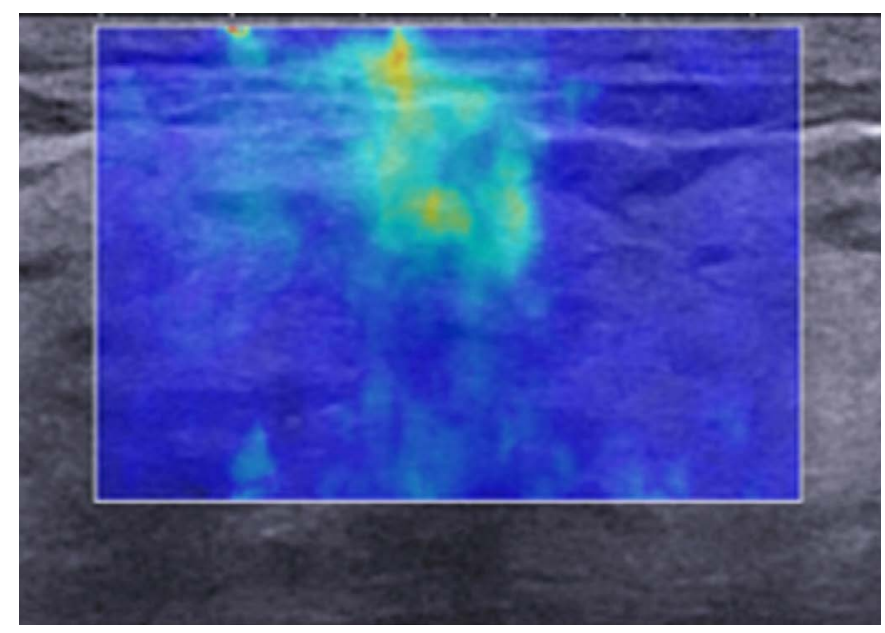

C

Fig. 4. Four color patterns on shear-wave elastography.

A. Pattern 1: no difference from the color around the lesion is observed at the margin of the lesion or in its interior. B. Pattern 2: a color that differs from the color around the lesion is observed at the margin or in the interior of the lesion, but it extends beyond the lesion and continues vertically in cords on the cutaneous side or the thoracic wall side. C. Pattern 3: a localized colored area is present at the margin of the lesion. D. Pattern 4: colored areas are present in the interior of the lesion heterogeneously.

up or to upgrade BI-RADS category 3 lesions to biopsy improved specificity from $61.1 \%$ for B-mode ultrasound alone to $78.5 \%$ by applying visual color stiffness or $77.4 \%$ by using $E_{\max }$ without changing the sensitivity [19]. This result is underscored by other studies suggesting that the addition of SWE reduced the number of unnecessary biopsies by enabling a switch to follow-up in benign BIRADS category $4 a$ lesions $[3,13,25,30]$. In addition, using the same criteria of the likelihood of malignancy as the BE1 study group, SWE helped downgrade benign BI-RADS category 3 lesions to category 2 and reduce the number of unnecessary initial short-term follow-up visits, especially when $\mathrm{E}_{\max }$ was $\leq 20 \mathrm{kPa}$ or the visual color stiffness was black to dark blue [42]. In clinical practice, SWE frequently helps

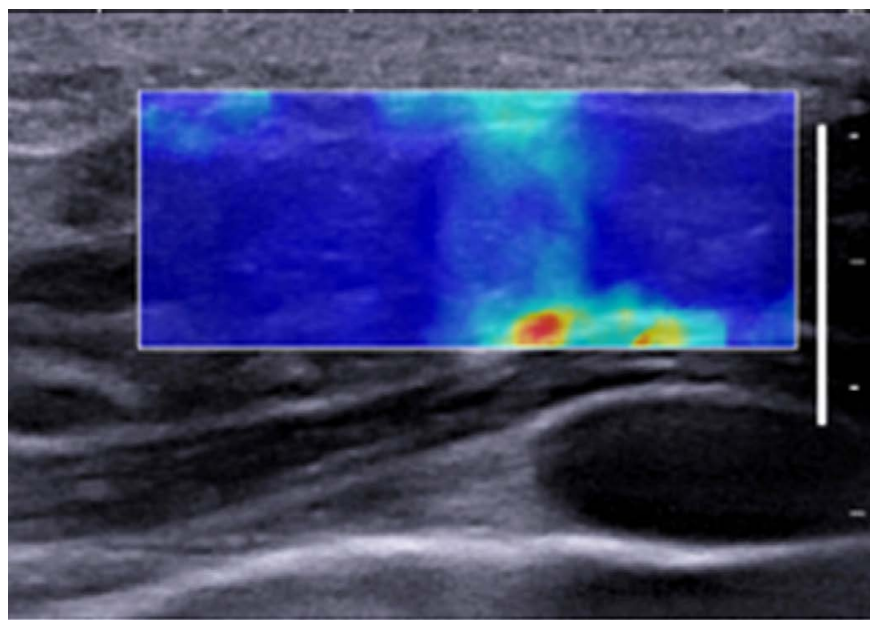

B

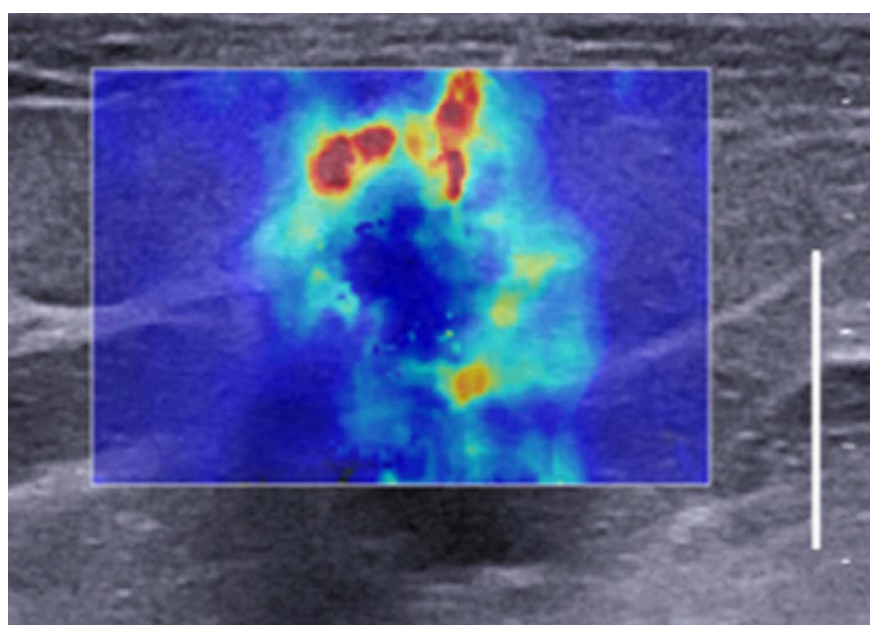

D 
cancer has been divided into four subtypes: luminal A, luminal B, human epidermal growth factor receptor 2 (HER2)-enriched, and basal cell-like subtypes, showing different clinical outcomes [44]. As a surrogate for molecular classification, immunohistochemical profiling for the expression of the hormonal receptors HER2 and Ki-67 has been suggested, and has been shown to be associated with different clinicopathological features, prognosis, and treatment responses [44]. Regarding SWE, a large invasive size, high nuclear grade, high histologic grade, and lymphovascular invasion were reported to be associated with increased stiffness of invasive breast cancer [44-47]. Estrogen receptor negativity, progesterone receptor negativity, p53 positivity, and Ki-67 positivity were significantly associated with a higher $E_{\text {ratior }}$ and triple-negative and HER2-positive tumors showed greater stiffness than estrogen receptor-positive tumors $[46,47]$. Interestingly, some aggressive tumors, such as highgrade cancers and triple-negative tumors, are likely to be assessed as BI-RADS category 3 in B-mode ultrasound, but SWE may provide additional information for diagnosing those benign-looking malignancies [47].

Predicting the axillary lymph node status in patients with newly diagnosed breast cancer is an integral component of breast cancer management, including the staging, treatment plan, and prognosis [48]. Ultrasonography has been performed for the noninvasive preoperative evaluation of the axillary nodal basin because it is widely available and easily incorporated into the standard workup for breast cancer patients [49]. Ultrasonographic criteria based on size or morphologic characteristics have shown variable diagnostic performance for metastatic lymph nodes [50]. In two previous studies - one in vivo and the other ex vivo - of SWE for sentinel axillary lymph nodes in patients with breast cancer [51,52], greater axillary lymph node stiffness was correlated with the risk of metastasis, and the high specificity of lymph node cortical stiffness can be complementary to B-mode ultrasound for decisionmaking regarding fine-needle aspiration biopsy. In future, further investigations of larger populations are needed to validate these results and apply SWE in clinical practice.

\section{Prediction of the Response of Breast Cancers to Neo- adjuvant Chemotherapy}

Neoadjuvant chemotherapy (NAC) has been applied as an established treatment strategy for tumor down-staging in patients with breast cancer who would not be optimally treated by immediate surgery [53]. A complete pathologic response after NAC may be a predictor of a low risk of subsequent recurrence and longer disease-free survival $[54,55]$. However, the response to NAC can be quite variable. The early and accurate prediction of responsive and resistant tumors to NAC is crucial to avoid futile chemotherapy and to guide more effective treatment strategies, such as modifying the chemotherapy regimen or optimizing the timing of surgery in nonresponsive patients $[53,55]$. A clinical examination combined with conventional imaging modalities has not yet become sensitive or specific enough to predict pathologic responses to NAC. Interestingly, recent studies have reported that increased stromal gene expression may be a predictor of response to NAC and that tumors with disorganized stroma had a reduced pathologic response to NAC, which means that stromal factors as well as tumor factors are important in predicting the response to NAC $[53,56,57]$. Considering that tumor stiffness is related to the collagen content in the stroma, stromal stiffness measured by SWE may be useful as an imaging biomarker for stromal structural abnormalities and the response to NAC $[20,53]$. Tumor elasticity measured by SWE before NAC had a significant relationship with a subsequent reduction in the cellularity of the primary tumor in response to NAC [20]. During $N A C$, the relative changes in tumor elasticity showed a significant correlation with the response to NAC, and the second NAC cycle was recommended as the optimal time point for performing SWE evaluations to reduce the chance of unnecessary cytotoxic exposure or to perform surgery in patients with NAC resistance $[53-55,58]$. A previous study suggested the optimal relative change in the stiffness threshold to be $-36.1 \%$, with a sensitivity of $73 \%$ and a specificity of $86 \%$, to distinguish between responders and nonresponders after two cycles of NAC [55].

\section{Pitfalls}

Although quantitative elasticity information obtained by SWE in addition to B-mode ultrasound has improved diagnostic performance, false results have been reported in $6.4 \%-36.6 \%$ of cases, in which the imaging results did not correspond to the pathologic results [59]. Specifically, the false-positive rates of benign masses (53\% using qualitative analysis and 22\%-37\% using quantitative analysis) were reported to be higher than the falsenegative rates of malignant masses ( $8 \%$ using qualitative analysis and $6 \%-10 \%$ using quantitative analysis) $[23,27]$. Considering that benign breast lesions showing false-positive SWE findings were significantly larger, the false-positive results can be explained by the size of the breast mass, as larger masses are likely to cause the probe to be unevenly applied to the skin above the masses, which could hinder adequate image acquisition [23]. Other lesionrelated factors contributing to false diagnoses in SWE may include the presence of pure in situ disease, smaller malignant masses, malignant masses with a circumscribed margin and an abrupt lesion boundary, and the grade of invasive disease $[23,27,60]$. Aside from the intrinsic tumor characteristics, patient-related or clinical factors 
associated with false elastography features include the mode of detection (symptomatic vs. mammography screening), age at diagnosis, breast thickness, lesion depth, distance from the nipple to the lesion, and the quality of the image $[23,27,59,60]$. When SWE examinations are performed and interpreted for breast masses, investigators should take into consideration the clinical and lesionrelated factors that are associated with inaccurate elastography findings.

\section{Summary}

Breast elastography is now an adjunct tool in breast ultrasonography. It is easily performed in clinical practice, adding only a short amount of time to breast ultrasonography. To ensure the best possible performance of SWE in the diagnosis of breast cancer, the technique should be optimized to acquire high-quality images, and practitioners should properly interpret the acquired images and data. One of the best applications of SWE is the characterization of breast masses categorized as BI-RADS category 3 and $4 a$, in order to attempt to reduce unnecessary breast biopsies. In addition, SWE can provide additional information on predicting breast cancer prognosis and response to NAC. However, the possibility of false-positive and false-negative results should be considered during interpretation. An adequate understanding of the features of each elastography method allows proper imaging and diagnosis to be carried out, confirming that elastography is indeed a clinically useful tool.

ORCID: Ji Hyun Youk: http://orcid.org/0000-0002-7787-780X; Hye Mi Gweon: http://orcid.org/0000-0002-3054-1532; Eun Ju Son: http://orcid.org/0000-00027895-0335

\section{Conflict of Interest}

No potential conflict of interest relevant to this article was reported.

\section{References}

1. Piccoli CW, Forsberg F. Advanced ultrasound techniques for breast imaging. Semin Roentgenol 2011;46:60-67.

2. Barr RG. Sonographic breast elastography: a primer. J Ultrasound Med 2012:31:773-783.

3. Youk JH, Son EJ, Gweon HM, Kim H, Park YJ, Kim JA. Comparison of strain and shear wave elastography for the differentiation of benign from malignant breast lesions, combined with B-mode ultrasonography: qualitative and quantitative assessments. Ultrasound Med Biol 2014;40:2336-2344.

4. Athanasiou A, Tardivon A, Tanter M, Sigal-Zafrani B, Bercoff J, Deffieux $T$, et al. Breast lesions: quantitative elastography with supersonic shear imaging: preliminary results. Radiology 2010;256:297-303.

5. Lee SH, Chang JM, Cho N, Koo HR, Yi A, Kim SJ, et al. Practice guideline for the performance of breast ultrasound elastography. Ultrasonography 2014;33:3-10.

6. Youk JH, Son EJ, Park AY, Kim JA. Shear-wave elastography for breast masses: local shear wave speed $(\mathrm{m} / \mathrm{sec})$ versus Young modulus (KPa). Ultrasonography 2014;33:34-39.

7. Zhou J, Zhan W, Chang C, Zhang X, Jia Y, Dong Y, et al. Breast lesions: evaluation with shear wave elastography, with special emphasis on the "stiff rim" sign. Radiology 2014;272:63-72.

8. Youk JH, Son EJ, Gweon HM, Han KH, Kim JA. Quantitative lesionto-fat elasticity ratio measured by shear-wave elastography for breast mass: which area should be selected as the fat reference? PLoS One 2015;10:e0138074.

9. Barr RG, Nakashima K, Amy D, Cosgrove D, Farrokh A, Schafer F, et al. WFUMB guidelines and recommendations for clinical use of ultrasound elastography: Part 2: breast. Ultrasound Med Biol 2015;41:1148-1160.

10. Nakashima K, Shiina T, Sakurai M, Enokido K, Endo T, Tsunoda H, et al. JSUM ultrasound elastography practice guidelines: breast. J Med Ultrason (2001) 2013;40:359-391.

11. Skerl K, Vinnicombe S, Giannotti E, Thomson K, Evans A. Influence of region of interest size and ultrasound lesion size on the performance of 2D shear wave elastography (SWE) in solid breast masses. Clin Radiol 2015;70:1421-1427.

12. Gweon HM, Youk JH, Son EJ, Kim JA. Visually assessed colour overlay features in shear-wave elastography for breast masses: quantification and diagnostic performance. Eur Radiol 2013;23:658-663.

13. Lee SH, Cho N, Chang JM, Koo HR, Kim JY, Kim WH, et al. Twoview versus single-view shear-wave elastography: comparison of observer performance in differentiating benign from malignant breast masses. Radiology 2014;270:344-353.

14. Youk JH, Gweon HM, Son EJ, Chung J, Kim JA, Kim EK. Threedimensional shear-wave elastography for differentiating benign and malignant breast lesions: comparison with two-dimensional shearwave elastography. Eur Radiol 2013;23:1519-1527.

15. Lee SH, Chang JM, Kim WH, Bae MS, Cho N, Yi A, et al. Differentiation of benign from malignant solid breast masses: comparison of two-dimensional and three-dimensional shear-wave elastography. Eur Radiol 2013;23:1015-1026.

16. Tanter M, Bercoff J, Athanasiou A, Deffieux T, Gennisson JL, Montaldo $G$, et al. Quantitative assessment of breast lesion viscoelasticity: initial clinical results using supersonic shear imaging. Ultrasound Med Biol 2008;34:1373-1386.

17. Evans A, Whelehan P, Thomson K, McLean D, Brauer K, Purdie $C$, et al. Quantitative shear wave ultrasound elastography: initial experience in solid breast masses. Breast Cancer Res 
2010;12:R104.

18. Chang JM, Moon WK, Cho N, Yi A, Koo HR, Han W, et al. Clinical application of shear wave elastography (SWE) in the diagnosis of benign and malignant breast diseases. Breast Cancer Res Treat 2011;129:89-97.

19. Berg WA, Cosgrove DO, Dore CJ, Schafer FK, Svensson WE, Hooley $R J$, et al. Shear-wave elastography improves the specificity of breast US: the BE1 multinational study of 939 masses. Radiology 2012;262:435-449.

20. Evans $A$, Armstrong $S$, Whelehan $P$, Thomson $K$, Rauchhaus $P$, Purdie $C$, et al. Can shear-wave elastography predict response to neoadjuvant chemotherapy in women with invasive breast cancer? Br J Cancer 2013;109:2798-2802.

21. Chang JM, Won JK, Lee KB, Park IA, Yi A, Moon WK. Comparison of shear-wave and strain ultrasound elastography in the differentiation of benign and malignant breast lesions. AJR Am J Roentgenol 2013;201:W347-W356.

22. Lee EJ, Jung HK, Ko KH, Lee JT, Yoon JH. Diagnostic performances of shear wave elastography: which parameter to use in differential diagnosis of solid breast masses? Eur Radiol 2013;23:1803-1811.

23. Yoon JH, Jung HK, Lee JT, Ko KH. Shear-wave elastography in the diagnosis of solid breast masses: what leads to false-negative or false-positive results? Eur Radiol 2013;23:2432-2440.

24. Yoon JH, Ko KH, Jung HK, Lee JT. Qualitative pattern classification of shear wave elastography for breast masses: how it correlates to quantitative measurements. Eur J Radiol 2013;82:2199-2204.

25. Youk JH, Gweon HM, Son EJ, Han KH, Kim JA. Diagnostic value of commercially available shear-wave elastography for breast cancers: integration into BI-RADS classification with subcategories of category 4. Eur Radiol 2013;23:2695-2704.

26. Au FW, Ghai S, Moshonov H, Kahn H, Brennan C, Dua H, et al. Diagnostic performance of quantitative shear wave elastography in the evaluation of solid breast masses: determination of the most discriminatory parameter. AJR Am J Roentgenol 2014;203:W328-W336.

27. Kim MY, Choi N, Yang JH, Yoo YB, Park KS. False positive or negative results of shear-wave elastography in differentiating benign from malignant breast masses: analysis of clinical and ultrasonographic characteristics. Acta Radiol 2015;56:1155-1162.

28. Skerl K, Vinnicombe S, Thomson K, McLean D, Giannotti E, Evans A. Anisotropy of solid breast lesions in 2D shear wave elastography is an indicator of malignancy. Acad Radiol 2016;23:53-61.

29. Tozaki M, Fukuma E. Pattern classification of ShearWave Elastography images for differential diagnosis between benign and malignant solid breast masses. Acta Radiol 2011;52:1069-1075.

30. Gweon HM, Youk JH, Son EJ, Kim JA. Clinical application of qualitative assessment for breast masses in shear-wave elastography. Eur J Radiol 2013;82:e680-e685.

31. Kim H, Youk JH, Gweon HM, Kim JA, Son EJ. Diagnostic performance of qualitative shear-wave elastography according to different color map opacities for breast masses. Eur J Radiol 2013;82:e326-e331.

32. Xiao Y, Yu Y, Niu L, Qian M, Deng Z, Qiu W, et al. Quantitative evaluation of peripheral tissue elasticity for ultrasound-detected breast lesions. Clin Radiol 2016;71:896-904.

33. Mendelson EB, Bohm-Velez M, Berg WA, Whitman GJ, Feldman MI, Madjar $\mathrm{H}$, et al. ACR BI-RADS Ultrasound. In: D'Orsi CJ, Sickles EA, Mendelson EB, Morris EA, eds. ACR BI-RADS Atlas, Breast Imaging Reporting and Data System. Reston, VA: American College of Radiology, 2013;1-173.

34. Evans A, Whelehan P, Thomson K, Brauer K, Jordan L, Purdie C, et al. Differentiating benign from malignant solid breast masses: value of shear wave elastography according to lesion stiffness combined with greyscale ultrasound according to BI-RADS classification. Br J Cancer 2012;107:224-229.

35. Wang ZL, Li JL, Li M, Huang Y, Wan WB, Tang J. Study of quantitative elastography with supersonic shear imaging in the diagnosis of breast tumours. Radiol Med 2013;118:583-590.

36. Klotz T, Boussion V, Kwiatkowski F, Dieu-de Fraissinette V, BaillyGlatre A, Lemery $S$, et al. Shear wave elastography contribution in ultrasound diagnosis management of breast lesions. Diagn Interv Imaging 2014;95:813-824.

37. Ko KH, Jung HK, Kim SJ, Kim H, Yoon JH. Potential role of shearwave ultrasound elastography for the differential diagnosis of breast non-mass lesions: preliminary report. Eur Radiol 2014;24:305-311.

38. Cebi Olgun D, Korkmazer B, Kilic F, Dikici AS, Velidedeoglu M, Aydogan $F$, et al. Use of shear wave elastography to differentiate benign and malignant breast lesions. Diagn Interv Radiol 2014;20:239-244.

39. Shi XQ, Li JL, Wan WB, Huang Y. A set of shear wave elastography quantitative parameters combined with ultrasound BI-RADS to assess benign and malignant breast lesions. Ultrasound Med Biol 2015;41:960-966.

40. Chen L, He J, Liu G, Shao K, Zhou M, Li B, et al. Diagnostic performances of shear-wave elastography for identification of malignant breast lesions: a meta-analysis. Jpn J Radiol 2014;32:592-599.

41. Liu B, Zheng Y, Huang G, Lin M, Shan Q, Lu Y, et al. Breast lesions: quantitative diagnosis using ultrasound shear wave elastography: a systematic review and meta-analysis. Ultrasound Med Biol 2016;42:835-847.

42. Schafer FK, Hooley RJ, Ohlinger R, Hahne U, Madjar H, Svensson $W E$, et al. ShearWave elastography BE1 multinational breast study: additional SWE features support potential to downgrade BIRADS(R)-3 lesions. Ultraschall Med 2013;34:254-259.

43. Cosgrove D, Piscaglia F, Bamber J, Bojunga J, Correas JM, Gilja OH, et al. EFSUMB guidelines and recommendations on the clinical use 
of ultrasound elastography. Part 2: Clinical applications. Ultraschall Med 2013;34:238-253.

44. Youk JH, Gweon HM, Son EJ, Kim JA, Jeong J. Shear-wave elastography of invasive breast cancer: correlation between quantitative mean elasticity value and immunohistochemical profile. Breast Cancer Res Treat 2013;138:119-126.

45. Evans A, Whelehan P, Thomson K, McLean D, Brauer K, Purdie C, et al. Invasive breast cancer: relationship between shear-wave elastographic findings and histologic prognostic factors. Radiology 2012;263:673-677.

46. Choi WJ, Kim HH, Cha JH, Shin HJ, Kim H, Chae EY, et al. Predicting prognostic factors of breast cancer using shear wave elastography. Ultrasound Med Biol 2014;40:269-274.

47. Chang JM, Park IA, Lee SH, Kim WH, Bae MS, Koo HR, et al. Stiffness of tumours measured by shear-wave elastography correlated with subtypes of breast cancer. Eur Radiol 2013;23:2450-2458.

48. Humphrey KL, Saksena MA, Freer PE, Smith BL, Rafferty EA. To do or not to do: axillary nodal evaluation after ACOSOG Z0011 Trial. Radiographics 2014;34:1807-1816.

49. Moorman AM, Bourez RL, de Leeuw DM, Kouwenhoven EA. Preoperative ultrasonographic evaluation of axillary lymph nodes in breast cancer patients: for which group still of additional value and in which group cause for special attention? Ultrasound Med Biol 2015;41:2842-2848.

50. Alvarez S, Anorbe E, Alcorta P, Lopez F, Alonso I, Cortes J. Role of sonography in the diagnosis of axillary lymph node metastases in breast cancer: a systematic review. AJR Am J Roentgenol 2006:186:1342-1348.

51. Tourasse C, Denier JF, Awada A, Gratadour AC, Nessah-Bousquet K, Gay J. Elastography in the assessment of sentinel lymph nodes prior to dissection. Eur J Radiol 2012;81:3154-3159.

52. Kilic F, Velidedeoglu M, Ozturk T, Kandemirli SG, Dikici AS, Er ME, et al. Ex vivo assessment of sentinel lymph nodes in breast cancer using shear wave elastography. J Ultrasound Med 2016;35:271277.
53. Ma Y, Zhang S, Zang L, Li J, Li J, Kang Y, et al. Combination of shear wave elastography and $\mathrm{Ki}-67$ index as a novel predictive modality for the pathological response to neoadjuvant chemotherapy in patients with invasive breast cancer. Eur J Cancer 2016;69:86-101.

54. Ma Y, Zhang S, Li J, Li J, Kang Y, Ren W. Comparison of strain and shear-wave ultrasounic elastography in predicting the pathological response to neoadjuvant chemotherapy in breast cancers. Eur Radiol 2017;27:2282-2291.

55. Jing $H$, Cheng W, Li ZY, Ying L, Wang QC, Wu T, et al. Early evaluation of relative changes in tumor stiffness by shear wave elastography predicts the response to neoadjuvant chemotherapy in patients with breast cancer. J Ultrasound Med 2016;35:16191627.

56. Farmer $\mathrm{P}$, Bonnefoi $\mathrm{H}$, Anderle $\mathrm{P}$, Cameron D, Wirapati P, Becette $V$, et al. A stroma-related gene signature predicts resistance to neoadjuvant chemotherapy in breast cancer. Nat Med 2009;15:6874.

57. Dekker TJ, Charehbili A, Smit VT, ten Dijke P, Kranenbarg EM, van de Velde CJ, et al. Disorganised stroma determined on pretreatment breast cancer biopsies is associated with poor response to neoadjuvant chemotherapy: results from the NEOZOTAC trial. Mol Oncol 2015;9:1120-1128.

58. Athanasiou A, Latorre-Ossa H, Criton A, Tardivon A, Gennisson JL, Tanter M. Feasibility of imaging and treatment monitoring of breast lesions with three-dimensional shear wave elastography. Ultraschall Med 2017;38:51-59.

59. Park SY, Choi JS, Han BK, Ko EY, Ko ES. Shear wave elastography in the diagnosis of breast non-mass lesions: factors associated with false negative and false positive results. Eur Radiol 2017;27:37883798.

60. Vinnicombe SJ, Whelehan P, Thomson K, McLean D, Purdie CA Jordan $L B$, et al. What are the characteristics of breast cancers misclassified as benign by quantitative ultrasound shear wave elastography? Eur Radiol 2014;24:921-926. 